\title{
Subtelomeric fluorescence in situ hybridization in clinical cytogenetics: results of analysis of Lithuanian patients
}

\author{
Vaidas Dirsé, \\ Vytautas Šliužas, \\ Živilè Čiuladaitè, \\ Beata Aleksiūnienè, \\ Vaidutis Kučinskas* \\ Department of Human \\ and Medical Genetics, \\ Faculty of Medicine, \\ Vilnius University, Vilnius, \\ Lithuania
}

Centre for Medical Genetics, Vilnius University Hospital Santariškiu Klinikos, Vilnius, Lithuania
Subtelomeric fluorescence in situ hybridization is one of the most useful methods in clinical cytogenetics. Usually, subtelomeric FISH is used for detection of subtelomeric rearrangements in patients with intellectual disability. In parallel with detection of subtelomeric deletions / duplications, we have applied subtelomeric FISH in detection or confirmation of different types of chromosome rearrangements: ring chromosomes, balanced translocations, recommbinat chromosomes, isochromosomes, mosaics.The analysis has been performed using the set of ToTelVysion ${ }^{\mathrm{TM}}$ subtelomeric FISH probes, Nikon Eclipse 80i epifluorescence microscope and LUCIAv1 software. Novel application of subtelomeric FISH indicates this method as a useful, precise and rapid way to diagnose the cytogenetic rearrangements.

Key words: subtelomeres, fluorescence in situ hybridization, intellectual disability, probe, chromosome rearrangements

\section{INTRODUCTION}

Fluorescence in situ hybridization (FISH) is a cytogenetic technique developed by Christoph Lengauer that is used to detect and localize the presence or absence of specific DNA sequences on chromosomes [1]. There are different variations and modifications of FISH method: spectral karyotyping (SKY), multiple in situ hybridization (M-FISH), genomic in situ hybridization (GISH), subtelomeric FISH. Standard application of subtelomeric FISH is detection of subtelomeric aberrations which have been reported to occur in approximately $2-5 \%$ of patients with intellectual

\footnotetext{
*Corresponding author. E-mail: Vaidutis.Kucinskas@santa.lt
}

disability (ID) [2, 3]. Some subtelomeric submicroscopic deletions result in well defined ID syndromes, such as monosomy 1 p36, Wolf-Hirschhorn syndrome (4 p-), and Cri-du-chat syndrome (5 p-), but for most subtelomeric defects a characteristic phenotype remains to be defined [3]. For this reason, screening of all subtelomeres is a valuable diagnostic tool.

In 1996, the first study to screen individuals with idiopathic ID using a complete set of FISH probes located within a distance of $300 \mathrm{~Kb}$ from the telomeric repeats was presented [4]. In other studies Ravnan et al. performed subtelomeric FISH screening for 11688 children with ID. These wide range studies estimated that the detection rate for clinically significant subtelomere abnormalities was 
approximately $2.5 \%{ }^{5}$. In this study we are presenting particular cases of application of subtelomeric FISH which is a powerful tool for detecting or confirming different types of chromosomal rearrangements: subtelomeric deletions / duplications, ring chromosomes, balanced translocations, recommbinat chromosomes, isochromosomes, mosaics.

\section{MATERIALS AND METHODS}

The set of subtelomeric FISH probes wasused for hybridization $\left(\right.$ ToTelVysion $^{\mathrm{TM}}$ ). The ToTelVysion ${ }^{\mathrm{TM}}$ Multi-color DNA FISH Probe Mixture consisted of a total 62 DNA FISH probes. The mixtures included various combinations of TelVysion ${ }^{\mathrm{TM}}, \mathrm{CEP}^{\circledR}$ and $\mathrm{LSI}^{\circledR}$ probes. The TelVysion $^{\mathrm{TM}}$ probes were homologous to DNA sequences specific to the $\mathrm{p}$ and $\mathrm{q}$ arm telomeric regions of each of the chromosomes (except the p arm of chromosomes 13, 14, 15, 21 and 22) and were mixed with blocking DNA. The TelVysion $^{\mathrm{TM}}$ probe contained a locus estimated to be within $300 \mathrm{~kb}$ of the end of the chromosome. In addition, several of the multi-color mixtures contained a unique sequence LSI $^{\circ}$ probes or alpha satellite CEP probe for purposes of identifying certain chromosomes within mixtures. The ToTelVysion $^{\mathrm{TM}}$ probes were directly labeled with either SpectrumOrange $^{\mathrm{TM}}$ and / or SpectrumGreen ${ }^{\mathrm{TM}}$ fluorophores. The $\mathrm{LSI}^{\circledR}$ and $\mathrm{CEP}^{\circledR}$ probes were labeled with SpectrumAqua ${ }^{\mathrm{TM}}$ fluorophore.

Chromosome slides have been prepared according to standard procedure form the cultivated lymphocyte culture. The hybridization of probes was performed according to manufacturer's protocol with minor modifications. Metaphase slides were pretreated with $2 \mathrm{X} \mathrm{SSC}(\mathrm{pH} 7)$ at $72{ }^{\circ} \mathrm{C}$ for $5 \mathrm{~min}$, followed by denaturation (70\% formamide / $2 \mathrm{X}$ SSC) (pH 7-8) at $72{ }^{\circ} \mathrm{C}$ for $5 \mathrm{~min}$ and $70 \%, 85 \%, 100 \%$ ethanol for $1 \mathrm{~min}$. each. After overnight hybridization $\mathrm{t}$ in a $37^{\circ} \mathrm{C}$ incubator, slides were washed with $0.4 \mathrm{X}$ SSC / 0.3\% $\mathrm{NP}-40$ at $72{ }^{\circ} \mathrm{C}$ for $2 \mathrm{~min}$. and with 2X SSC / 0.1\% NP-40 at ambient temperature for $2 \mathrm{~min}$. Metaphases were dyed by applying $3 \mu \mathrm{L}$ DAPI-II counterstain to each target area of the slide. The slides were analyzed by Nicon Eclipse 80i epifluorescence microscope and the images captured by a CCD camera. The complete analysis and interpretation were performed using the LUCIA v2 software. A minimum of five metaphases and 10 interphase nuclei are required to analyse (the area of each target) for each target area.

\section{RESULTS}

\section{Detection of subtelomeric deletions}

For detection of subtelomeric deletions / duplications 33 unrelated patients with ID/developmental delay (DD) and with dysmorphic features and / or (multiple) congenital anomalies were referred to the Centre for Medical Genetics at Vilnius University Hospital, Santariškių Klinikos, Vilnius. Prior to FISH analysis a routine cytogenetic karyotype examination was performed. All patients had normal karyotype. Subtelomeric FISH analysis of 33 patients has revealed two subtelomeric aberrations - a monosomy of chromosome $1 \mathrm{q}$ and a monosomy of chromosome $5 \mathrm{q}$ (Figs. 1-2).

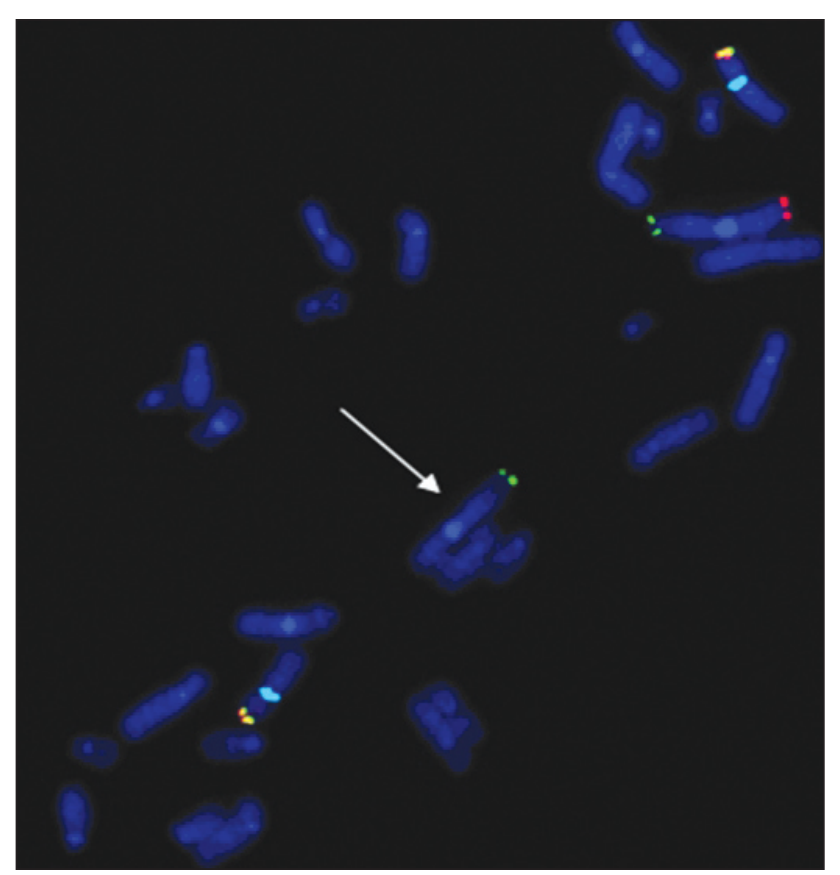

Fig. 1. Image using chromosome 1 probe mixture (TelVysion 1p SpectrumGreen, TelVysion 1q Spectrum0range, TelVysion Xp/Yp Spectrum0range and SpectrumGreen, (EP X SpectrumAqua). The arrow shows a 1q subtelomeric deletion

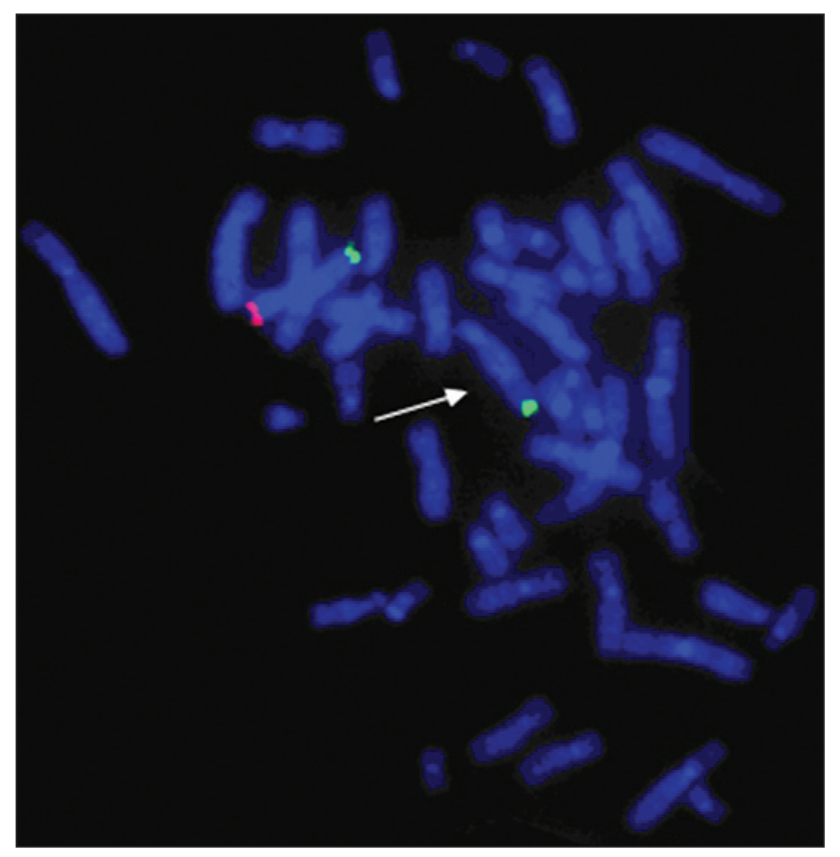

Fig. 2. TelVysion $5 p$ SpectrumGreen, TelVysion $5 q$ Spectrum0range. The arrow shows a $5 q$ subtelomeric deletion 


\section{Confirmation of balanced translocations}

Conventional G-banded karyotype analysis from GTG banded metaphases estimated balanced $t(2,12)$ and $t(4,18)$ translocations in 2 patients. Subtelomeric FISH was successfully applied for confirmation and specification of these detected translocations. In the patient with $\mathrm{t}(2,12)$ we used ToTelVys-

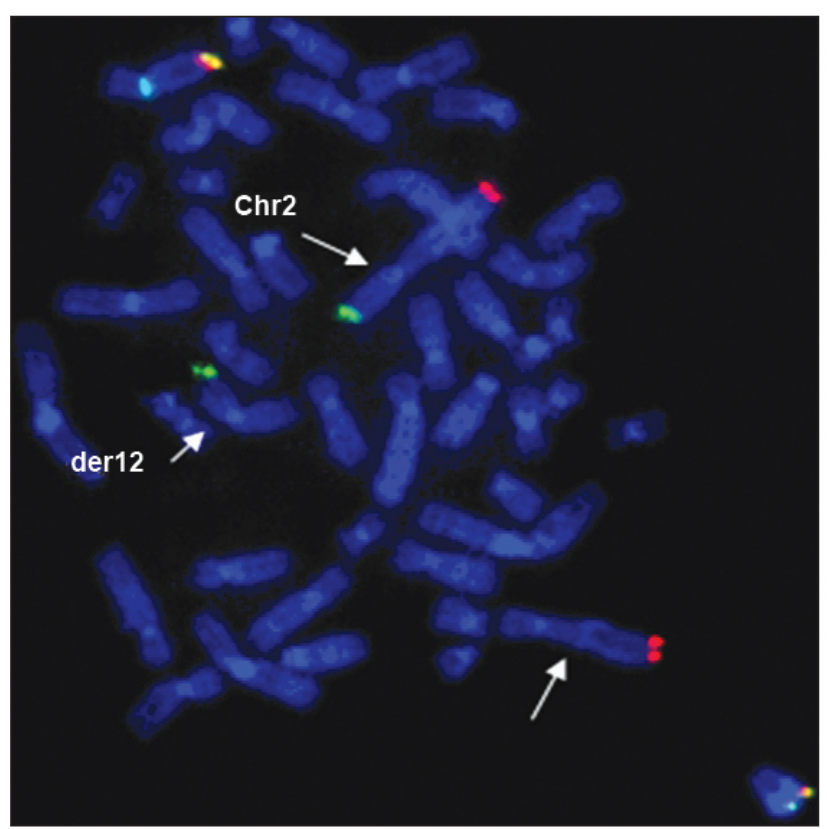

Fig. 3. Image using chromosome 2 probe mixture (TelVysion $2 p$ SpectrumGreen, TelVysion $2 q$ Spectrum0range, TelVysion Xq/Yq Spectrum0range and SpectrumGreen, (EP X SpectrumAqua). The arrows show a normal chromosome 2 and the derivative chromosomes 2 and 12

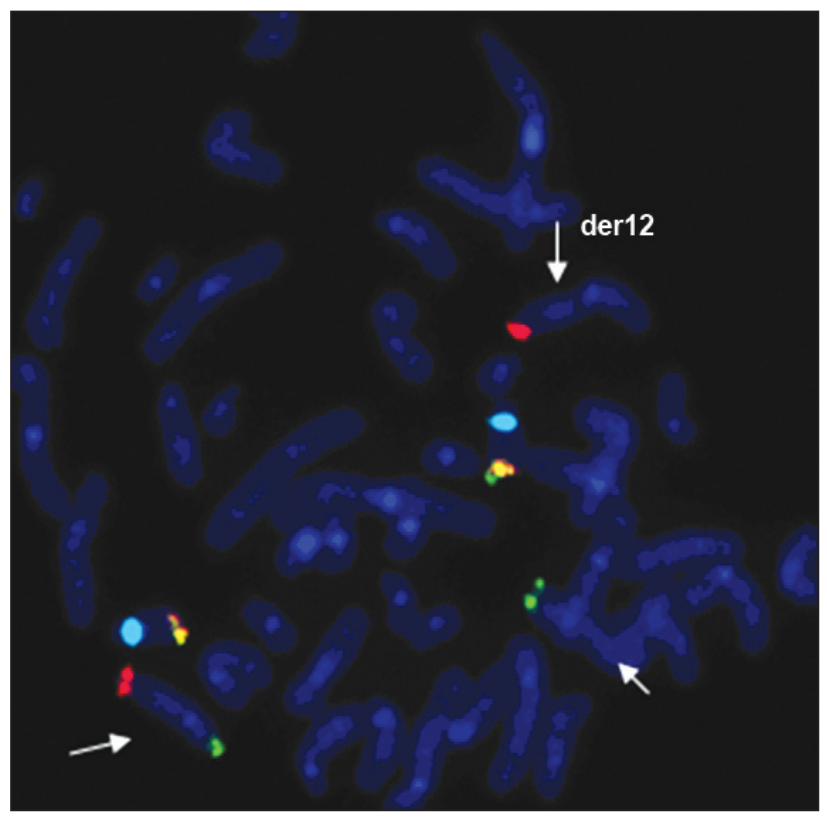

Fig. 4. Image using chromosome 12 probe mixture (TelVysion 12p SpectrumGreen, TelVysion 12q Spectrum0range, TelVysion 18q Spectrum0range and SpectrumGreen, (EP 18 SpectrumAqua). The arrows show a normal chromosome 12 and the derivative chromosomes 2 and 12 ion $^{\mathrm{TM}}$ probe mixture for chromosome 2 (probe mixture consisted of these subtelomeric probes: $2 \mathrm{p}$ (green), $2 \mathrm{q}$ (orange), Xq / Yq (yellow), X centromeric (aqua)) (Fig. 3); while for chromosome 12 (probe mixture consisted of these subtelomeric probes: $12 \mathrm{p}$ (green), $12 \mathrm{q}$ (orange), $18 \mathrm{q}$ (yellow), 18 centromeric (aqua)) (Fig. 4). FISH analysis confirmed the translocation between chromosome 2 and chromosome 12 . The picture of chromosome's 2 probe mixture showed no green signal on 2 p, the green signal was on the other chromosome. The picture of chromosome's 12 probe mixture showed no green signal on $12 \mathrm{p}$, the green signal was on the other chromosome. Comparing these two pictures we estimated translocation ish $\mathrm{t}(2,12)$ (pter-,qter+; pter-,qter+).

In the patient with $t(4,18)$ we used ToTelVysion ${ }^{\mathrm{TM}}$ probe mixture for chromosome 4 (probe mixture consisted of these subtelomeric probes: $4 \mathrm{p}$ (green), $4 \mathrm{q}$ (orange), $21 \mathrm{q}$ (yellow), 21 (LSI AML aqua)) (Fig. 5) and for chromosome 12 (probe mixture consisted of these subtelomeric probes: $12 \mathrm{p}$ (green), $12 \mathrm{q}$ (orange), $18 \mathrm{q}$ (yellow), 18 centromeric (aqua)) (Fig. 6). FISH analysis confirmed the translocation between chromosome 4 and chromosome 18 too. The picture of chromosome's 4 probe mixture showed no green signal $4 \mathrm{p}$, the green signal was on the other chromosome. The picture of chromosome's 12 probe mixture showed no yellow signal on $18 \mathrm{q}$, the yellow signal was on the other chromosome. Comparing these two pictures we estimated translocation ish $\mathrm{t}(4,18)$ (pter-, qter+; pter+, qter-).

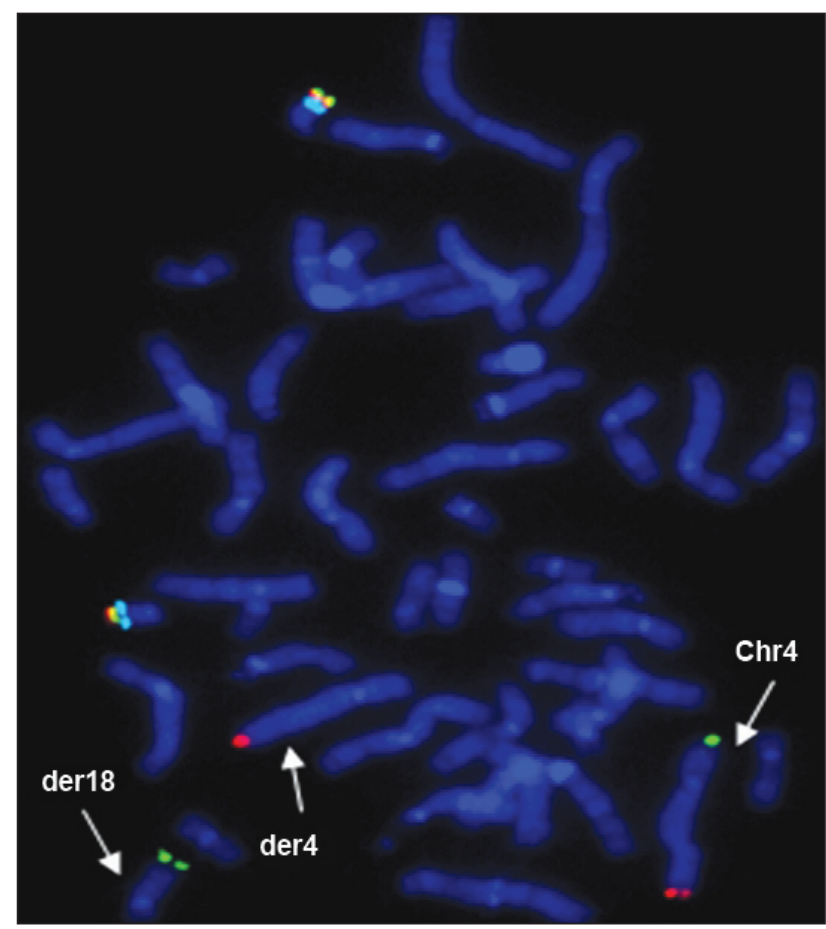

Fig. 5. Image using chromosome 4 probe mixture (TelVysion $4 p$ SpectrumGreen, TelVysion 4q Spectrum0range, TelVysion 21q Spectrum0range and SpectrumGreen, LSI AML 21q SpectrumAqua). The arrows show a normal chromosome 4 and the derivative chromosomes 4 and 18 


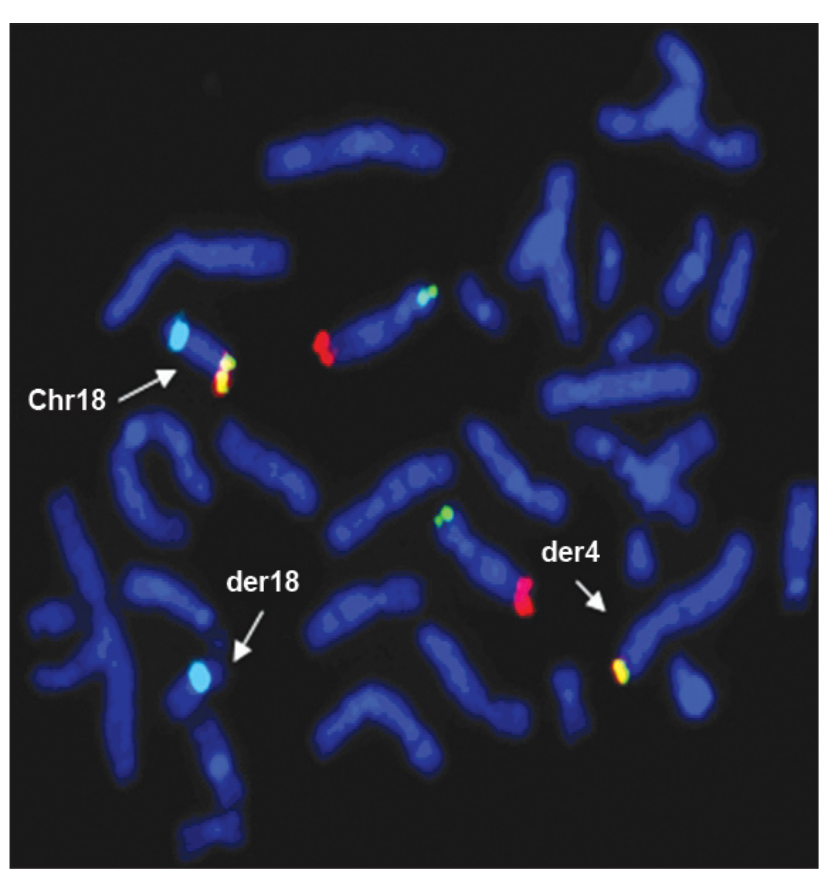

Fig. 6. Image using chromosome 12 probe mixture (TelVysion 12p SpectrumGreen, TelVysion 12q Spectrum0range, TelVysion 18q Spectrum0range and SpectrumGreen, (EP 18 SpectrumAqua). The arrows show a normal chromosome 18 and the derivative chromosome 4 and 18

Detection of the origin of the additional euchromatic material

Conventional G-banded karyotype analysis from GTG banded chromosomes revealed the karyotype 46,XY,der(6) $\operatorname{add}(6)(q 24)$ in all cells. Chromosomal analysis of the proband's parents showed normal karyotypes, indicating that abnormality mentioned above was de novo. In order to identify the origin of the additional material, FISH analysis, using subtelomeric specific probes for all long and short arms of chromosomes, was performed. The picture of chromosome's 6 probe mixture (probe mixture consisted of these subtelomeric probes: $6 \mathrm{p}$ (green), $6 \mathrm{q}$ (orange), $13 \mathrm{q}$ (yellow), 13 (LSI aqua)) (Fig. 7) showed two green signals on both arms of chromosome 6. FISH analysis of this picture revealed the duplication of the $6 \mathrm{p}$ subtelomeric region on the $6 \mathrm{q}$ subtelomeric region and deletion of 6 q subtelomeric region - ish $\operatorname{der}(6)($ qter-, pter+).

\section{Confirmation of ring chromosomes}

$46, \mathrm{XY}, \mathrm{r}(5)(\mathrm{p} 15 \mathrm{q} 35)$ karyotype was revealed by analysis of conventional G-banded karyotyping. We performed subtelomeric FISH to specify the breakpoints of this aberration. ToTelVysion ${ }^{\mathrm{TM}}$ probe mixture for chromosome 5 (probe mixture consisted of these subtelomeric probes: $5 \mathrm{p}$ (green), $5 \mathrm{q}$ (orange) was used in this analysis. The picture of chromosome's 5 probe mixture showed no red signal on the ring

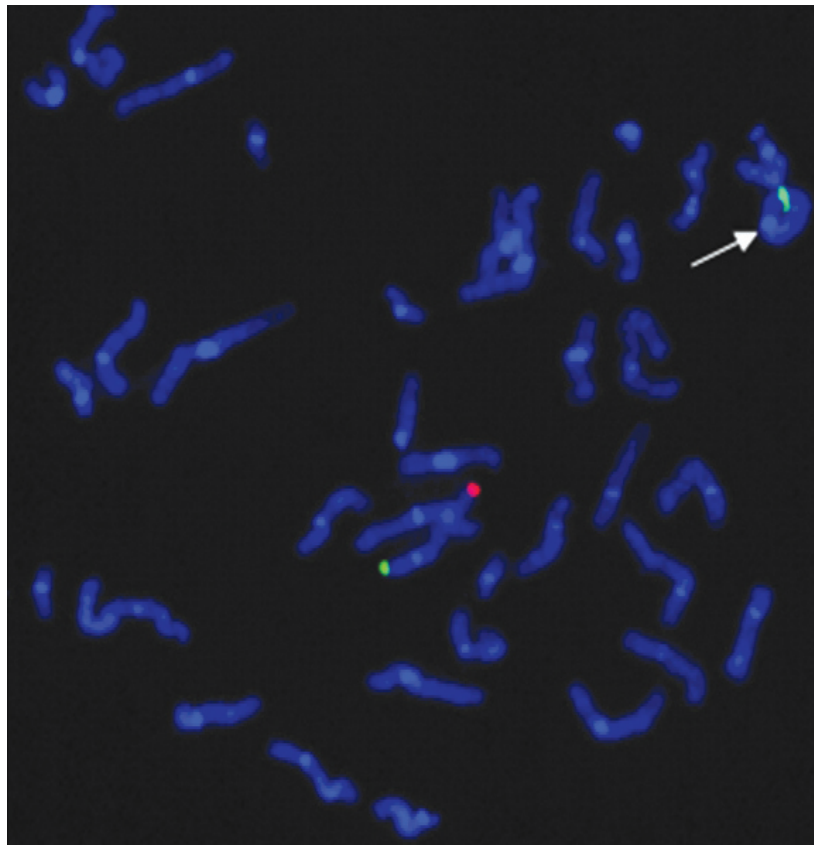

Fig. 7. Image using chromosome 5 probe mixture (TelVysion $5 p$ SpectrumGreen, TelVysion $5 q$ Spectrum 0 range). The arrow shows a ring chromosome 5

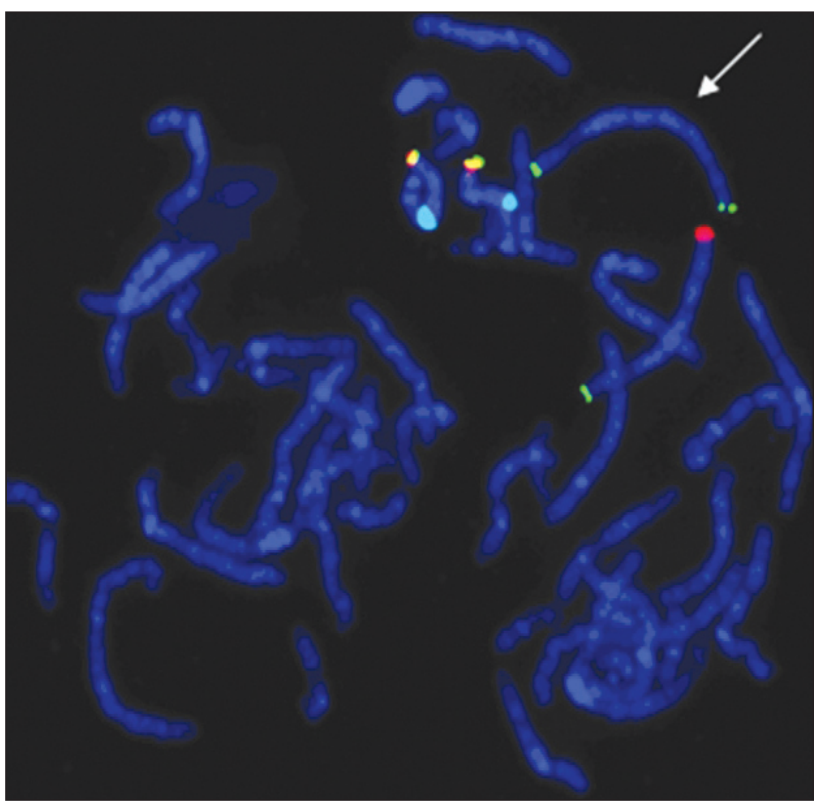

Fig. 8. Image using chromosome 6 probe mixture (TelVysion $6 p$ SpectrumGreen, TelVysion $6 q$ Spectrum0range, TelVysion $13 q$ Spectrum0range and SpectrumGreen, LSI 13 (13q14) SpectrumAqua). The arrow shows a recombinant chromosome 6

$5 \mathrm{q}$, the green signal was on the ring $5 \mathrm{p}$ (Fig. 8). Since no red signal on the ring $5 \mathrm{q}$ was detected, we postulated that the breakpoint is above subtelomeric region of the ring chromosome 5. The green signal on the ring chromosome $5 \mathrm{p}$ validates that the breakpoint is on the distal segment of chromosome 5 . 
Detection of isochromosomes and mosaicisms

Conventional G-banded karyotype analysis from GTG banded metaphases showed two cell lines, 45, $\mathrm{X}$ and $46, \mathrm{X}, \mathrm{i}(\mathrm{Xq10})$. We used subtelomeric FISH to confirm the presence of isochromosome $\mathrm{X}$ and determine the percentage of these two cell lines. ToTelVysion ${ }^{\mathrm{TM}}$ probe mixture for chromosome Xp (probe mixture consisted of these

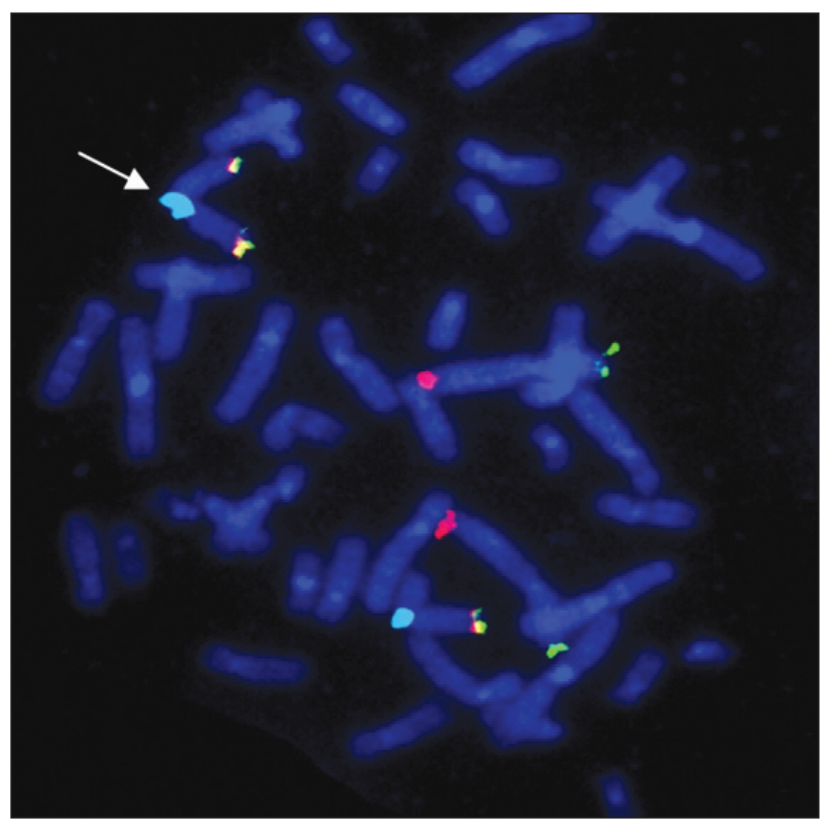

Fig. 9. Image using chromosome 1 probe mixture (TelVysion 1p SpectrumGreen, TelVysion 1q Spectrum0range, TelVysion Xp/Yp Spectrum0range and SpectrumGreen, (EP X SpectrumAqua). The arrow shows an isochromosome $X$

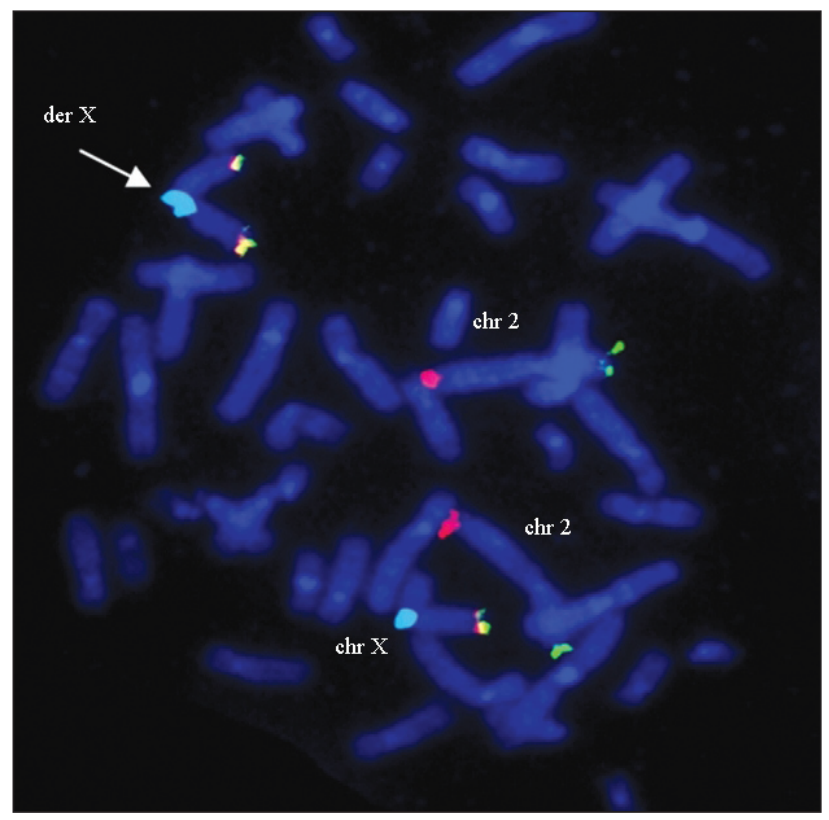

Fig. 10. Image using chromosome 2 probe mixture (TelVysion 2p SpectrumGreen, TelVysion 2q Spectrum0range, TelVysion Xq/Yq Spectrum0range and SpectrumGreen, (EP X SpectrumAqua). The arrow shows an isochromosome $X$ subtelomeric probes: $1 \mathrm{p}$ (green), 1 q (orange), Xp / Yp centromeric (aqua)) and for chromosome Xq (probe mixture consisted of these subtelomeric probes: $2 \mathrm{p}$ (green), 2 q (orange), 18 q (yellow), Xq / Yq centromeric (aqua)) were used in this analysis. The picture of chromosome's Xp probe mixture showed one yellow signal on one chromosome $\mathrm{X}$ and no yellow signal on the other chromosome $X$ (Fig. 9). Two aqua signals were detected on both chromosome's X centromeric regions. The picture of chromosome's Xq probe mixture showed three yellow signals. One yellow signal was detected on normal chromosome X long arm, the other two yellow signals were found on both arms of isochromosome X (Fig. 10). Analysis of these pictures verifies isochormosome $\mathrm{X}$ to be comprised of two long arms of chromosome X. Using subtelomeric FISH analysis, we identified the $1: 1$ ratio of $45, \mathrm{X}$ vs. $46, \mathrm{X}, \mathrm{i}(\mathrm{Xq} 10)$ cell lines.

\section{DISCUSSION}

We have presented a practical application of subtelomeric FISH as a helpful cytogenetic method in resolving complicated clinical cytogenetic cases. Generally, subtelomeric FISH is used for screening of subtelomeric rearrangements (microduplications / microdeletions) in patients with ID. However, we applied subtelomeric FISH for confirming balanced translocations, ring chromosomes, detection the origin of the additional euchromatic materials, isochromosomes, mosaicism, etc.

We have detected $1 \mathrm{q}$ and $5 \mathrm{q}$ subtelomeric deletions in patients with ID using subtelomeric FISH. Terminal deletions of chromosome 5 long arm are very rare. Comparing our results with those published by other authors we should notice that the monosomy 5 qter was not even detected in a comprehensive FISH subtelomere analysis (study) of 11,688 cases [5]. However, two siblings with monosomy 5qter were identified in a subtelomeric study of 250 children with ID [6]. An interstitial deletion within 5 q35.1 was identified by array CGH in a study of 140 children with ID [7]. Subtelomeric FISH analysis of the patient with Torrielo-Carey syndrome detected 1 q subtelomeric deletion. Deletions of the long arm of chromosome 1 have been reported in numerous publications, with the breakpoints occurring along the entire length of the $\mathrm{q}$ arm, thus causing a variety of clinical features [8]. Patients with terminal deletion of the distal part of the long arm of chromosome 1 have a recognizable phenotype, including ID, microcephaly, growth retardation, a distinct facial appearance and various midline defects [9]. We presented $1 \mathrm{q}$ terminal deletion as a genetic cause of ID of our patient with Torrielo-Carey syndrome.

Subtelomeric FISH was purposefully applied for confirming of balanced translocations. From all detected 
translocations, two - $t(2,12)$ and $t(4,18)$ were selected for FISH analysis because the results obtained by G-banded chromosome analysis were ambiguous with unclear size, cytogenetic position and origin of these aberrations. The translocation between chromosome 4 and chromosome 18 was identified by conventional G-banded karyotype analysis in a woman, but subtelomeric FISH analysis was applied in prenatal analysis of the fetus of this translocation carrier for detection balanced / unbalanced translocation in the fetus karyotype. Combining different subtelomeric FISH probe mixtures, we validated these two translocations. This analysis reveals subtelomeric FISH as a specific and rapid method for confirming and specifying different types of balanced translocations.

Breakpoints of ring chromosomes may be specified by subtelomeric FISH too. Conventional G-banded chromosome analysis revealed the 46,XY,r(5)(p15q35) karyotype. FISH analysis showed a subtelomeric deletion on $5 \mathrm{q}$ and no subtelomeric deletion on $5 \mathrm{p}$. Although the subtelomeric region of $5 \mathrm{q}$ is deleted, we postulate that the breakpoint of chromosome 5 long arm is approximately within q35 cytogenetic band. The breakpoint of chromosome $5 \mathrm{p}$ might be on the telomeric part of chromosome because subtelomeric region of the short arm is not deleted.

Subtelomeric FISH method is very useful in detecting the origin of the additional euchromatic material since conventional karyotyping is not able to do it. In our case using FISH analysis we consider that the derivative chromosome 6 was comprised due to pericentric inversion which has occurred in the germline of one of the parents followed by genetic recombination between inverted and normal chromosomes 6 or shortly after fertilization in the proband cells.

We have performed a subtelomeric FISH technique in one case of mosaicism with isochromosome X. Conventional G-banded karyotype analysis in prenatal period detected fetus karyotype 45,X [4] / 46,X,i(Xq10) [13]. In postnatal period we performed conventional karyotyping and subtelomeric FISH to confirm the results of prenatal analysis and to specify the ratio of mosaicism. Comparing two subtelomeric FISH probe mixtures in this analysis we saw two different types of images of isochromosome X. These results not only reveal the rearrangement of chromosome $\mathrm{X}$ but also specify the ratio of mosaicism much more precisely rather than the conventional karyotyping.

The cases described above emphasize the need of combining the conventional G-banding with different FISH methodologies.

\section{References}

1. Lengauer C, Green ED, Cremer T. Fluorescence in situ hybridization of YAC clones after Alu-PCR amplification. Genomics 1992; 13(3): 826-8.

2. Knight SJ, Flint J. Perfect endings: a review of subtelomeric probes and their use in clinical diagnosis. J Med Genet 2000; 37(6): 401-9.

3. De Vries BB, Winter R, Schinzel A, van RavenswaaijArts C. Telomeres: a diagnosis at the end of the chromosomes. J Med Genet 2003; 40(6): 385-98.

4. Flint J, Wilkie AO, Buckle VJ, Winter RM, Holland AJ, McDermid HE. The detection of subtelomeric chromosomal rearrangements in idiopathic mental retardation. Nat Genet 1995; 9(2): 132-40.

5. Ravnan JB, Tepperberg JH, Papenhausen P, Lamb AN, Hedrick J, Eash D, Ledbetter DH, Martin CL. Subtelomere FISH analysis of 11688 cases: an evaluation of the frequency and pattern of subtelomere rearrangements in individuals with developmental disabilities. J Med Genet 2006; 43(6): 478-89.

6. Baker E, Hinton L, Callen DF, Altree M, Dobbie A, Eyre HJ, Sutherland GR, Thompson E, Thompson P, Woollatt E, Haan E. Study of 250 children with idiopathic mental retardation reveals nine cryptic and diverse subtelomeric chromosome anomalies. Am J Med Genet 2002; 107(4): 285-93.

7. Menten B, Maas N, Thienpont B, Buysse K, Vandesompele J, Melotte C, de Ravel T, Van Vooren S, Balikova I, Backx L, Janssens S, De Paepe A, De Moor B, Moreau Y, Marynen P, Fryns JP, Mortier G, Devriendt K, Speleman F, Vermeesch JR. Emerging patterns of cryptic chromosomal imbalance in patients with idiopathic mental retardation and multiple congenital anomalies: a new series of 140 patients and review of published reports. J Med Genet 2006; 43(8): 625-33.

8. Gentile M, Di Carlo A, Volpe P, Pansini A, Nanna P, Valenzano MC, Buonadonna AL. FISH and cytogenetic characterization of a terminal chromosome 1q deletion: clinical case report and phenotypic implications. Am J Med Genet A 2003; 117A(3): 251-4.

9. van Bon BW, Koolen DA, Borgatti R, Magee A, GarciaMinaur S et al. Clinical and molecular characteristics of 1qter microdeletion syndrome: delineating a critical region for corpus callosum agenesis/hypogenesis. J Med Genet 2008; 45(6): 346-54. 
Vaidas Dirsė, Vytautas Šliužas, Živilè Čiuladaitè,

Beata Aleksiūnienè, Vaidutis Kučinskas

SUBTELOMERŲ FLUORESCENCINĖS IN SITU

HIBRIDIZACIJOS METODAS KLINIKINĖJE

CITOGENETIKOJE: LIETUVOS PACIENTŲ TYRIMŲ

REZULTATAI

\section{Santrauka}

Subtelomerų fluorescencinès in situ hibridizacijos metodas šiuo metu yra vienas dažniausiai naudojamų klinikinejjè citogenetikoje. Iprastai subtelomerų FISH yra naudojamas nustatant chromosomų subtelomerų mikrodelecijas / mikroduplikacijas pacientams su psichikos negalia. Be subtelomerinių persitvarkymų analizès, šis metodas buvo taikytas įvairiems chromosomų persitvarkymams: nustatyti bei patvirtinti subalansuotas reciprokines translokacijas, žiedines chromosomas, rekombinantines chromosomas, izochromosomas, mozaikas. Tyrimai buvo atlikti naudojant ToTelVysion ${ }^{\mathrm{TM}}$ subtelomerų FISH žymenų rinkinius, Nikon Eclipse 80i epifluorescencinį mikroskopą ir LUCIAv1 kompiuterinę analizavimo sistemą. Subtelomerų FISH metodo praktinis taikymas praplečia diagnostikos galimybes, kurios leidžia tiksliai bei greitai identifikuoti ar patvirtinti ịvairius chromosomų persitvarkymus klinikineje citogenetikoje.

Raktažodžiai: subtelomeros, fluorescencinè in situ hibridizacija, žymenys, mikrodelecijos / mikroduplikacijos, chromosomų persitvarkymai 